\title{
Preemptive analgesia in dental implant surgery: A systematic review and meta-analysis of randomized controlled trials
}

\author{
Gustavo Henrique Mattos-Pereira ${ }^{1}$, Carolina Castro Martins ${ }^{2}$, Rafael Paschoal Esteves-Lima ${ }^{3}$, Rachel \\ Alvarenga-Brant ${ }^{4}$, Luís Otávio Miranda Cota ${ }^{5}$, Fernando Oliveira Costa ${ }^{6}$
}

${ }^{1}$ ORCID: 0000-0003-0176-0741. DDS, MS, PhD candidate. Department of Clinical Dentistry, Pathology and Oral Surgery, Faculty of Dentistry, Federal University of Minas Gerais, Belo Horizonte, Brazil

${ }^{2}$ ORCID: 0000-0001-9072-3226. DDS, MS, PhD, Associate Professor. Department of Pediatric Dentistry, Faculty of Dentistry, Federal University of Minas Gerais, Belo Horizonte, Brazil

${ }^{3}$ ORCID: 0000-0003-4343-3845. DDS, MS, PhD, Adjunct Professor. Department of Clinical Dentistry, Pathology and Oral Surgery, Faculty of Dentistry, Federal University of Minas Gerais, Belo Horizonte, Brazil

${ }^{4}$ ORCID: 0000-0001-9358-2262. DDS, Master student. Department of Clinical Dentistry, Pathology and Oral Surgery, Faculty of Dentistry, Federal University of Minas Gerais, Belo Horizonte, Brazil

${ }^{5}$ ORCID: 0000-0003-1517-5842. DDS, MS, PhD, Associate Professor. Department of Clinical Dentistry, Pathology and Oral Surgery, Faculty of Dentistry, Federal University of Minas Gerais, Belo Horizonte, Brazil

${ }^{6}$ ORCID: 0000-0002-7687-1238. DDS, MS, PhD, Titular Professor. Department of Clinical Dentistry, Pathology and Oral Surgery, Faculty of Dentistry, Federal University of Minas Gerais, Belo Horizonte, Brazil

Correspondence:

Antônio Carlos Ave., 6627

Pampulha, Belo Horizonte, $M G$

Zip code: 31270-901, Brazil

ghmattos75@gmail.com

Received: 09/02/202

Accepted: 28/06/202

Mattos-Pereira GH, Martins CC, Esteves-Lima RP, Alvarenga-Brant R, Cota LO, Costa FO. Preemptive analgesia in dental implant surgery: A systematic review and meta-analysis of randomized controlled trials. Med Oral Patol Oral Cir Bucal. 2021 Sep 1;26 (5):e632-41.

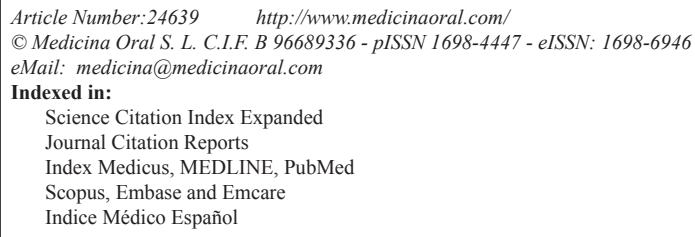

\begin{abstract}
Background: To assess the effectiveness of preemptive analgesia in dental implant surgery in randomized controlled trials (RCTs).

Material and Methods: The present study was conducted in accordance with the guidelines of the Preferred Reporting Items for Systematic Reviews and Meta-Analyses (PRISMA) statement and registered in PROSPERO database CRD42020168757. A search without restrictions regarding language or date of publication was conducted in six databases and gray literature. A random effect meta-analysis compared the efficacy of preemptive analgesia compared to placebo through pooled OR and $95 \% \mathrm{CI}$. The interpretation of results followed the certainty of evidence using the Grading of Recommendations, Assessment, Development and Evaluation (GRADE) approach together with the magnitude of the effect according to GRADE guidelines.

Results: Four studies were included in the review and three were incorporated into the meta-analysis. All studies demonstrated that preemptive analgesia contributed to a significant improvement in the postoperative pain control. However, the overall pooled standard mean difference (SMD) showed that preemptive analgesia had small effects compared to placebo in reducing pain (SMD: -0.45 ; IC: -0.83 ; -0.08 ) with low certainty of the evidence.
\end{abstract}


Our meta-analysis showed that the magnitude of the effect was bigger six to eight hours after the surgery (large effect), compared to the time of one to two hours after the surgery (small effect).

Conclusions: Preemptive analgesia may have a positive effect in reducing pain compared to not using preemptive medication, but the evidence is very uncertain.

Key words: Preemptive analgesia, postoperative pain, dental implant surgery, systematic review.

\section{Introduction}

Acute postoperative pain is a normal response to surgical interventions. It is one of the causes of late recovery and post-operative analgesic medication use, often indiscriminate (1).

Among the alternatives for improving postoperative pain control, preemptive analgesia has stood out. Preemptive analgesia consists of administering analgesic medication before tissue injury, that is, before the reception, transmission, modulation, and nociception of the aggressive stimulus, aiming to prevent hyperalgesia and the consequent stimulus that amplifies pain (2). Preemptive analgesia has been used as an effective for pain control method in third molar surgeries (3), also presenting itself as a viable protocol for dental implant surgeries (4).

In implant dentistry, the installation of dental implants comprises a surgical procedure that can generate mild to moderate pain sensations, but which may exceed the normal thresholds in some moments (2). In order to establish an efficient preemptive analgesic effect, it is necessary that an ideal level of antinociceptive medication is administered before the injury and that it remains in the postoperative phase, thus preventing sensitization during the inflammatory phase (5).

There are several groups of analgesic agents used in dentistry, as well as different dosages to be implemented. Therefore, defining which one has the best therapeutic efficacy remains a challenge for dental surgeons $(1,3,6)$. Therefore, due to the conflicting results in the literature, this systematic review and meta-analysis aims to evaluate the effectiveness of preemptive analgesia in dental implant surgeries.

\section{Material and Methods}

- Protocols and Records

These systematic review and meta-analysis were conducted in accordance with the recommendations of the Preferring Reporting Items for Systematic Reviews and Meta-analyzes (PRISMA) (7). A study protocol was registered with the International Prospective Register of Systematic Reviews PROSPERO, under the number CRD42020168757.

- Eligibility criteria

The clinical question (PICO question) was as follows: "Does preemptive analgesia decrease postoperative pain in patients undergoing dental implant surgery?"

Patient (P): patients undergoing dental implant surgery; Intervention (I): preemptive analgesia using any medication evaluated in clinical trials; Comparison (C): patients who used a placebo as preemptive medication or no treatment; Outcome $(\mathrm{O})$ : postoperative pain.

- Inclusion criteria

We included parallel arm randomized placebo-controlled trials (RCTs), with healthy patients above 18 years old, and who had undergone surgery to insert dental implants (single or multiple), who received any type of preemptive medication (analgesic or anti-inflammatories), considering that the medication administration time was not established. No minimum follow-up time of the studies was determined.

The exclusion criteria were non-randomized trials and observational studies, studies without placebo or no treatment as a control group, animal studies, systematic reviews, literature reviews, conference proceedings, editorials, and studies that were not written in the English language.

- Information sources

An electronic search was conducted from the intersection up to January 2020 and updated in December 2020 in the following databases: MedLine through PubMed, Scopus (Elsevier), Web of Science, Latin American and Caribbean Health Sciences Literature (Lilacs) through Virtual Health Library (Bireme), Cochrane Central Register of Controlled Trials (CENTRAL) and Cochrane Database of Systematic Reviews. A manual search was conducted on the included studies and reviews. No restrictions were imposed on the year of publication. The research strategies used in each database are displayed in Table 1.

- Selection of studies

All the retrieved articles were organized in the EndNote Web program.

The selection of the studies took place in two phases and was conducted by two independent reviewers (GHMP and RPEL). First, the reviewers screened titles and abstracts for eligibility. Studies without enough information to make a decision were selected for fulltext screening. Full texts were obtained and analyzed for further selection. In the case of disagreement, the reviewers discussed the eligibility criteria until a consensus was reached. 
Table 1: Terms used in the search.

Medline through PubMed

((preemptive analgesia OR preoperative administration OR pain measurement OR postoperative pain OR cyclooxygenase inhibitors OR acute inflammation) AND (dental implant surgery OR dental implants OR dental implant))

\section{Scopus}

TITLE-ABS-KEY (“preemptive analgesia” OR “preoperative administration” OR "pain measurement” OR "postoperative pain"

OR “cyclooxygenase inhibitors" OR “acute inflammation” ) AND TITLE-ABS-KEY ( "dental implant surgery" OR "dental implant*")

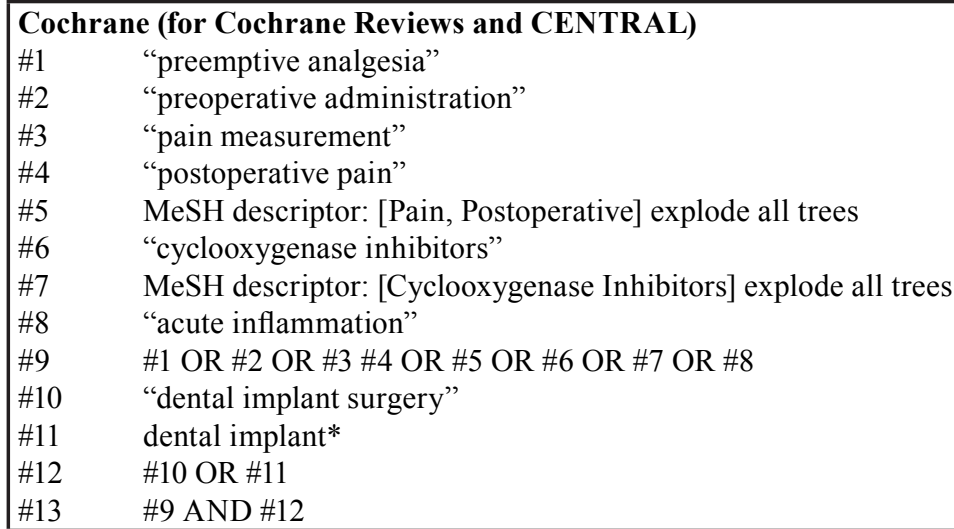

\section{Web of Science}

TS=((“preemptive analgesia” OR "preoperative administration" OR "pain measurement” OR "postoperative pain" OR “cyclooxygenase inhibitors" OR "acute inflammation”) AND (“dental implant surgery" OR "dental implant*”))

\section{LILACS}

(“preemptive analgesia" OR "preoperative administration" OR "pain measurement" OR "postoperative pain" OR "cyclooxygenase inhibitors" OR "acute inflammation") [Palavras] and (dental implant surgery" OR “dental implant*”) [Palavras]

\section{- Data extraction}

Two independent reviewers extracted data (GHMP and RPEL). The following data were extracted from each study in an excel spreadsheet previously created: name of the author (s) and year of publication, country, sample size, sex, age, duration of surgery, anesthetic drug used, drop-outs, tested medication, rescue medication, time when preemptive medication was administered, methods for assessing pain and adverse effects.

- Risk of Bias Assessment

The risk of bias was assessed using the Cochrane Bias Risk Tool for Randomized Trials (RoB 2.0) and judged as "low", "some concerns" or "high" (8).

- Outcomes

The primary outcomes were pain from one to two hours after surgery and from six to eight hours after surgery. For each outcome we extracted mean or median scores of pain and respective standard deviation (SD), standard error (SE) or 95\% CI, when reported by authors. We used the software Review Manager version 5.4 for meta-analysis for these two primary outcomes. The mean and standard deviation were used to calculate the pooled standard mean difference (SMD) and its 95\% CI. We used random effect model considering uncertainty in 12 test for heterogeneity when few studies are used. Moreover, the diversity may occur in meta-analysis with inevitable heterogeneity (8). We subgrouped each outcome for the type of drug comparing to placebo or no medication as the comparison group.

- Summary of results and the certainty of the evidence The certainty of the evidence was assessed through Grading of Recommendations, Assessment, Development and Evaluation tool (GRADE) (9).

RCTs start with high certainty of evidence, and it can be rated down due to problems as risk of bias, inconsistency, indirectness, imprecision, and publication bias. Each outcome was tabulated in a Summary of Finding (SoF) table using GRADEpro. For the magnitude of the effect, we used the Cohen's effect sizes for SMD: from -0.2 to 0.2 representing a trivial or no effect; -0.5 to -0.2 or 0.2 to 0.5 representing a small effect; -0.8 to -0.5 or 0.5 to 0.8 representing a moderate effect; and $<-0.8$ or $>0.8$ representing a large effect $(10)$. The interpretation of the results was based on an integrated approach of the magnitude of the effect based on Cohen's effect size and the certainty of the evidence (11).

\section{Results}

- Selection of studies

One thousand two hundred and thirty five studies were retrieved in the electronic search. After analyzing titles and abstracts, twenty three studies were selected for 
evaluation through full reading. The main reasons for exclusion after full texts evaluation were studies that: did not use preemptive medication or placebo as a control group, studies that were not clinical trials, and those not written in English. Four studies were included (4,1214) in the review and three in the meta-analysis (12-14). Flowchart 1 shows the screening process (Fig. 1). Three $(4,13,14)$ of the four selected studies reported having been registered prior to patient recruitment.

- Characteristics of studies

The characteristics of the four included studies are shown in Table 2. The studies were conducted in four different countries. The randomized trials included 326 patients, and 294 patients completed the trials with a drop-out rate of $9.8 \%$ of the total number of patients. The number of patients varied from 40 to 117 . In the four included studies, a single-implant surgery was performed. Regarding the area of implant placement, only one trial has reported its location that was the posterior region of the mandible (12).

The preemptive medication used were: $4 \mathrm{mg}$ dexamethasone (4), 600mg ibuprofen $(4,14), 25 \mathrm{mg}$ dexketoprofen trometamol (13), and 40mg piroxicam (12), with placebo as control in all studies. In all trials, the participants were allowed to have analgesic rescue medication in any time they needed. There was no restriction regarding minimum time for taking the rescue medication neither for pain score, in a way that patients were free to decide whether to use it or not $[4,154]$. In two studies $(12,13)$, analgesic and anti-inflammatory medication were prescribed to be taken regardless of the level of pain.

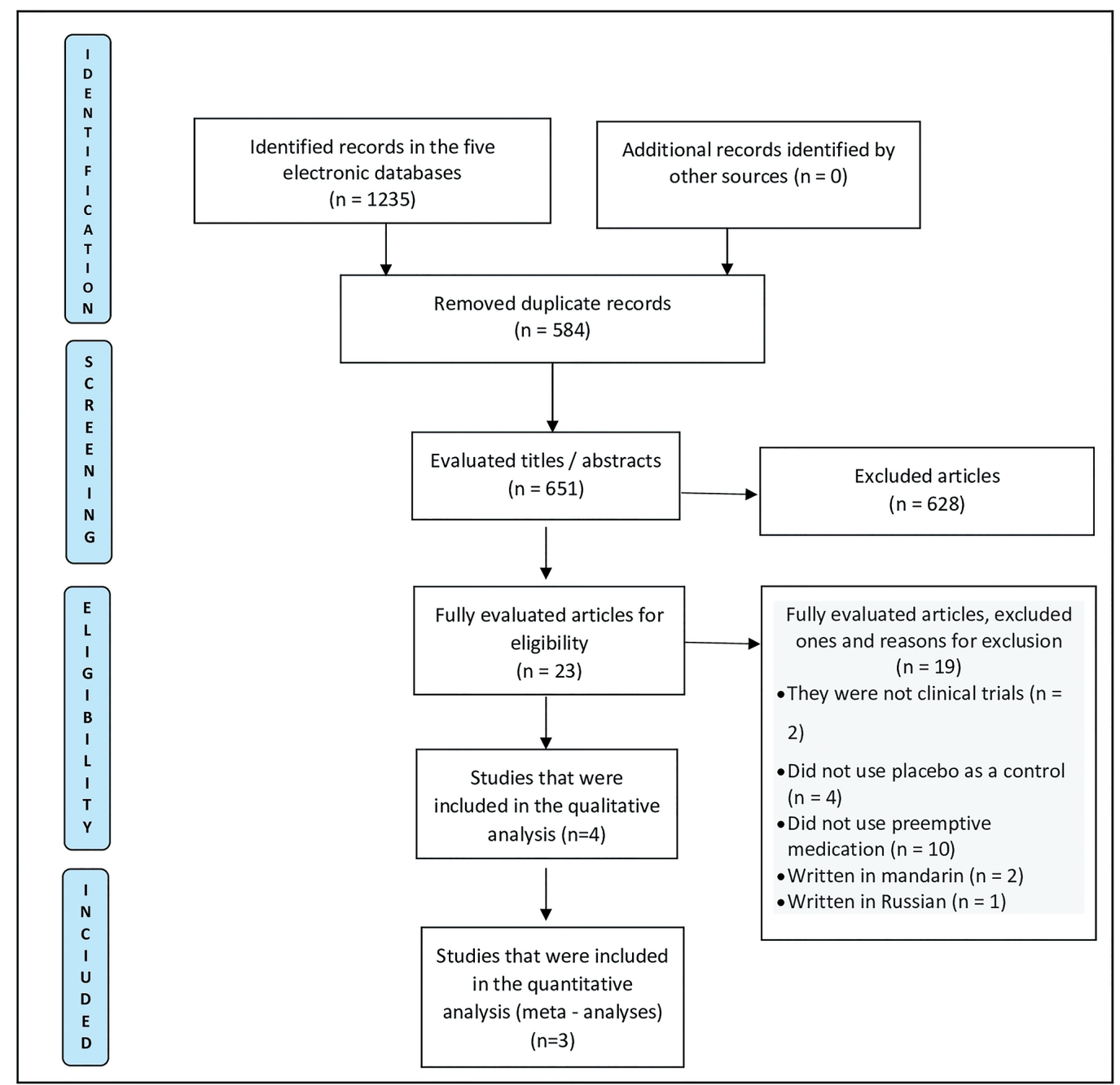

Moher D, Liberati A, Tetzlaff J, Altman DG; PRISMA Group. Preferred reporting items for systematic reviews and metaanalyses: the PRISMA statement. PLoS Med. 2009; 6:e1000097.

Fig. 1: Preferred Reporting Items for Systematic Reviews and Meta-Analyses (PRISMA) flowchart of study screening selection. 
Table 2: Characteristics of the included studies.

\begin{tabular}{|c|c|c|c|c|c|c|c|c|c|c|}
\hline Authors & Country & Intervention & $\begin{array}{l}\text { Sample } \\
\text { size (n) }\end{array}$ & $\begin{array}{l}\text { Gen- } \\
\text { der }\end{array}$ & $\begin{array}{c}\text { Age } \\
\text { (years) }\end{array}$ & $\begin{array}{l}\text { Rescue } \\
\text { Drug }\end{array}$ & $\begin{array}{l}\text { Pain As- } \\
\text { sessment }\end{array}$ & $\begin{array}{l}\text { Anes- } \\
\text { thetic } \\
\text { used }\end{array}$ & $\begin{array}{l}\text { Dura- } \\
\text { tion of } \\
\text { surgery }\end{array}$ & $\begin{array}{c}\text { Side } \\
\text { effects }\end{array}$ \\
\hline $\begin{array}{l}\text { Baham- } \\
\text { mam et al. } \\
2017\end{array}$ & $\begin{array}{l}\text { Saudi } \\
\text { Arabia }\end{array}$ & $\begin{array}{c}\text { Preemptive } \\
\text { medication with } \\
\text { Dexamethasone/ } \\
\text { Ibuprofen } 01 \mathrm{~h} \\
\text { before }\end{array}$ & $\begin{array}{l}117 \text { pa- } \\
\text { tients }\end{array}$ & $\begin{array}{l}71(\mathrm{M}) \\
46(\mathrm{~F})\end{array}$ & $\begin{array}{c}38,4 \pm \\
10,5\end{array}$ & $\begin{array}{l}1 \mathrm{G} \text { Acet- } \\
\text { aminophen }\end{array}$ & $\begin{array}{l}\text { VAS, } \\
\text { VRS and } \\
\text { NRS }\end{array}$ & $\begin{array}{c}\text { Lido- } \\
\text { caine } 2 \% \\
1: 100.000\end{array}$ & $\begin{array}{c}30-45 \\
\min \end{array}$ & $\begin{array}{l}\text { Not } \\
\text { related }\end{array}$ \\
\hline $\begin{array}{l}\text { Sánchez- } \\
\text { Pérez et } \\
\text { al. } 2018\end{array}$ & Spain & $\begin{array}{c}\text { Preemptive } \\
\text { medication with } \\
\text { Dexcetoprophe- } \\
\text { no Trometamol } \\
15 \text { min before }\end{array}$ & $\begin{array}{l}83 \text { pa- } \\
\text { tients }\end{array}$ & $\begin{array}{c}29(\mathrm{M}) \\
53(\mathrm{~F})\end{array}$ & 52,7 & $\begin{array}{l}600 \mathrm{mg} \mathrm{de} \\
\text { Ibuprofen }\end{array}$ & VAS & $\begin{array}{l}\text { Lido- } \\
\text { caine }\end{array}$ & $\begin{array}{l}40-60 \\
\min \end{array}$ & $\begin{array}{l}\text { Inflam- } \\
\text { mation }\end{array}$ \\
\hline $\begin{array}{c}\text { Pereira et } \\
\text { al. } 2020\end{array}$ & Brazil & $\begin{array}{c}\text { Preemptive } \\
\text { medication with } \\
\text { Ibuprofen } 01 \mathrm{~h} \\
\text { before }\end{array}$ & $\begin{array}{l}54 \text { pa- } \\
\text { tients }\end{array}$ & $\begin{array}{l}21(\mathrm{M}) \\
33(\mathrm{~F})\end{array}$ & $37-74$ & $\begin{array}{c}750 \mathrm{mg} \mathrm{de} \\
\text { Paracetamol }\end{array}$ & VAS & $\begin{array}{l}\text { Prilo- } \\
\text { caine }\end{array}$ & $60 \mathrm{~min}$ & $\begin{array}{l}\text { Not } \\
\text { related }\end{array}$ \\
\hline $\begin{array}{c}\text { Bhutani et } \\
\text { al. } 2019\end{array}$ & India & $\begin{array}{c}\text { Preemptive } \\
\text { medication with } \\
\text { Piroxicam 40mg } \\
\text { sub lingual }\end{array}$ & $\begin{array}{l}40 \text { pa- } \\
\text { tients }\end{array}$ & UI & $16-40$ & $\begin{array}{l}\text { Piroxicam } \\
20 \mathrm{mg}\end{array}$ & VAS & UI & UI & $\begin{array}{l}\text { Swell- } \\
\text { ing }\end{array}$ \\
\hline
\end{tabular}

M, male; F, female; UI: uninformed; VAS: visual analogic scale; VRS: verbal rating scale; NRS: numeric rating scale

- Assessment of preemptive medication

The time for administering preemptive medication in most of the included studies was 1 hour before the procedure $(4,12,14)$. In one study $(13)$, preemptive medication was administered $15 \mathrm{~min}$ before surgical intervention. All studies used the Visual Analogic Scale (VAS) for pain assessment, one study also used the Numeric Rate Scale (NRS) (4) and one trial also used the Verbal Rating Scale (VRS) (4), thus, the comparative analysis of the level of pain between the studies, took into account the scores obtained by the VAS scale, common to all studies. Pain assessment times varied from the immediate postoperative period (13) to 07 days after the surgical procedure (4). The follow-up time of the included studies varied from 1 to 168 hours (mean time 78.4 hours).

- Side effects

All studies collected data on side effects (12-14). The most common reported side effects were edema (12) that presented a significant decrease in the test group but not in the control group. In another study (13), significant differences between the test group and the control group for inflammation and bleeding were noted. The control group had a lower degree of inflammation; however, it obtained a higher degree of bleeding than the test group. No side effects like infections, major edema and bleeding were observed (14).

- Bias Risk Assessment

We contacted authors for risk of bias and data extraction when the information was unclear in the text, with only two $(13,14)$ of the four authors responding. Table 3 presents the results for the assessment of risk of bias. All the studies that were analyzed showed "some concerns" on the final judgment.

- Meta-analysis of postoperative pain

Fig. 2 shows the comparison between preemptive medication versus placebo 1-2 hours after the surgical procedure, divided in subgroups according to the type of drug.

Table 3: Risk of bias.

\begin{tabular}{|c|c|c|c|c|c|c|}
\hline Study & $\begin{array}{c}\text { Randomization } \\
\text { process }\end{array}$ & $\begin{array}{c}\text { Deviation } \\
\text { from intended } \\
\text { intervention }\end{array}$ & $\begin{array}{c}\text { Missing } \\
\text { outcome data }\end{array}$ & $\begin{array}{c}\text { Measurement } \\
\text { of the outcome }\end{array}$ & $\begin{array}{c}\text { Selection } \\
\text { of reported } \\
\text { outcome }\end{array}$ & $\begin{array}{c}\text { Risk of bias } \\
\text { judgment }\end{array}$ \\
\hline Bahamman 2017 & 1 & 1 & 2 & 3 & 2 & 2 \\
\hline Sanchez-Perez 2018 & 2 & 1 & 2 & 1 & 2 & 2 \\
\hline Mattos-Pereira 2020 & 2 & 1 & 1 & 1 & 2 & 2 \\
\hline Bhutani 2019 & 1 & 1 & 1 & 2 & 2 & 2 \\
\hline
\end{tabular}

Full description is on Higgins JP, Thompson SG, Deeks JJ, Altman DG. Measuring inconsistency in meta-analyses. BMJ. 2003 ; 327 : 557-60. 1-Low risk of bias 2-Some concerns 3-Hight risk of bias 4-Uninformed. 


\begin{tabular}{|c|c|c|c|c|c|c|c|c|c|c|c|}
\hline \multirow[b]{2}{*}{ Study or Subgroup } & \multicolumn{3}{|c|}{ preemptive medication } & \multicolumn{3}{|c|}{ placebo } & \multicolumn{2}{|c|}{ Std. Mean Difference } & \multirow{2}{*}{\multicolumn{3}{|c|}{$\begin{array}{l}\text { Std. Mean Difference } \\
\text { IV, Random, } 95 \% \mathrm{Cl}\end{array}$}} \\
\hline & Mean & SD & Total & Mean & SD & Total & Weight & IV, Random, 95\% Cl & & & \\
\hline \multicolumn{12}{|c|}{ 1.1.1 dexketoprofen trometamol versus placebo } \\
\hline $\begin{array}{l}\text { Sánchez-Pérez et al., } 2018 \\
\text { Subtotal }(95 \% \mathrm{Cl})\end{array}$ & 1.23 & 2.11 & $\begin{array}{l}41 \\
41\end{array}$ & 1.54 & 1.38 & $\begin{array}{l}42 \\
42\end{array}$ & $\begin{array}{l}42.9 \% \\
42.9 \%\end{array}$ & $\begin{array}{l}-0.16[-0.59,0.27] \\
-0.16[-0.59,0.27]\end{array}$ & & & \\
\hline \multicolumn{12}{|c|}{$\begin{array}{l}\text { Heterogeneity: Not applicable } \\
\text { Test for overall effect: } Z=0.72(P=0.47)\end{array}$} \\
\hline \multicolumn{12}{|c|}{ 1.1.3 ibuprofen versus placebo } \\
\hline $\begin{array}{l}\text { Mattos-Pereira et al., } 2020 \\
\text { Subtotal }(95 \% \mathrm{Cl})\end{array}$ & 0.15 & 0.36 & $\begin{array}{l}27 \\
27\end{array}$ & 0.34 & 1.05 & $\begin{array}{l}27 \\
27\end{array}$ & $\begin{array}{l}31.4 \% \\
31.4 \%\end{array}$ & $\begin{array}{l}-0.74[-1.29,-0.19] \\
-0.74[-1.29,-0.19]\end{array}$ & & & \\
\hline \multicolumn{12}{|c|}{ Heterogeneity: Not applicable } \\
\hline \multicolumn{12}{|c|}{ 1.1.4 piroxicam versus placebo } \\
\hline $\begin{array}{l}\text { Bhutani et al., } 2019 \\
\text { Subtotal }(95 \% \mathrm{Cl})\end{array}$ & 0.4 & 0.66 & $\begin{array}{l}20 \\
20\end{array}$ & 0.8 & 0.67 & $\begin{array}{l}20 \\
20\end{array}$ & $\begin{array}{l}25.8 \% \\
25.8 \%\end{array}$ & $\begin{array}{l}-0.59[-1.22,0.05] \\
-0.59[-1.22,0.05]\end{array}$ & & & \\
\hline \multicolumn{12}{|c|}{ Heterogeneity: Not applicable } \\
\hline Total $(95 \% \mathrm{Cl})$ & & & 88 & & & 89 & $100.0 \%$ & $-0.45[-0.83,-0.08]$ & & & \\
\hline $\begin{array}{l}\text { Heterogeneity: } \operatorname{Tau}^{2}=0.04 \\
\text { Test for overall effect: } Z=2.3 \\
\text { Test for subaroup difference }\end{array}$ & $\begin{array}{l}\mathrm{hi}^{2}=2.99 \\
(P=0.02) \\
\mathrm{Chi}^{2}=2.9\end{array}$ & $2(P=$ & $\begin{array}{l}22) ; 1^{2}= \\
=0.22) .\end{array}$ & $=33 \%$ & & & & & $\begin{array}{ll} & 1 \\
-4 & -2 \\
\text { preemptive me }\end{array}$ & edication placebo & 4 \\
\hline
\end{tabular}

Fig. 2: Forest plot for primary outcome 1-2 hours.

Overall pooled SMD showed that preemptive medication had a small effect in reducing pain (SMD: -0.45; IC: $-0.83 ;-0.08)$ when compared to placebo, with low certainty of the evidence. However, only Ibuprofen had large effect compared to placebo (SMD: -0.74; CI: -1.29; -0.19). Fig. 3 shows the comparison between preemptive medication versus placebo 6-8 hours after the surgical procedure. Preemptive medication had a large effect (SMD $=-2.10 ; 95 \% \mathrm{CI}:-4.24 ; 0.04)$ when compared to placebo, with very low certainty of the evidence. Subgroup anal- ysis showed that both ibuprofen (SMD $=-1.09 ; 95 \% \mathrm{CI}$ : $-1.66 ;-0.51$ ) and piroxicam ( $\mathrm{MD}=-5.80 ; 95 \% \mathrm{CI}:-7.28$; -4.33) had a large effect when compared to placebo.

- Certainty of the evidence

The certainty of the evidence was rated down due to problems of risk of bias and imprecision for pain 1-2 hours after surgery. For 6-8 hours after surgery, the certainty of the evidence was rated down due to serious problems of risk of bias, inconsistency, and imprecision (Fig. 4).

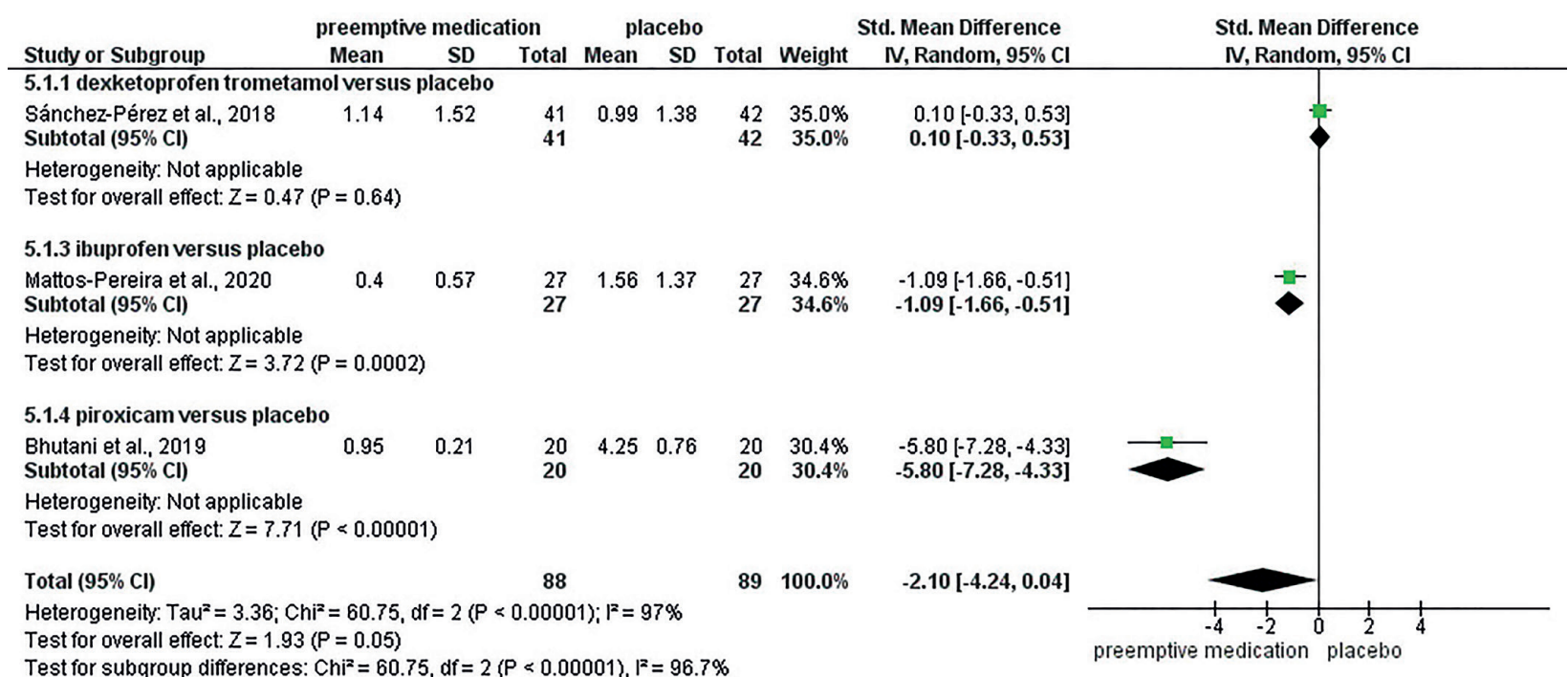

Fig. 3: Forest plot for primary outcome 6-8 hours. 


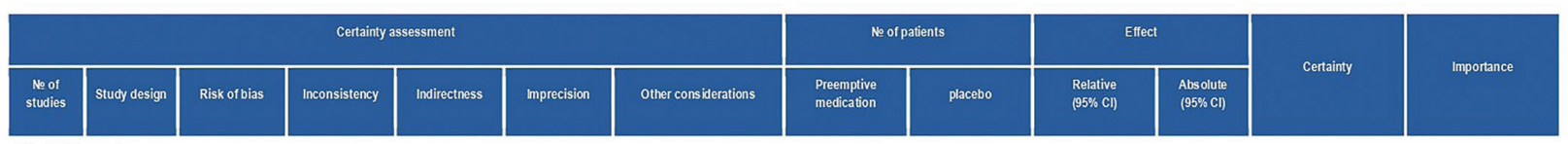

Pain 1 to 2 hours after surgery

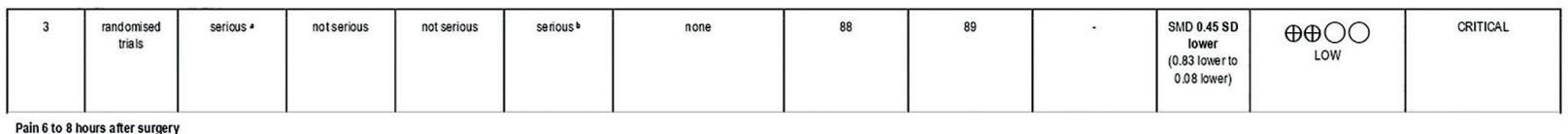

\begin{tabular}{|c|c|c|c|c|c|c|c|c|c|c|c|c|}
\hline 3 & $\begin{array}{l}\text { randonised } \\
\text { trials }\end{array}$ & serious: & senious" & not serious & senious & none & 88 & 89 & . & $\begin{array}{c}\text { SMD 2.1 SD } \\
\text { lower } \\
\text { (4.24 lowert to } \\
0.04 \text { lower) }\end{array}$ & $\underset{\text { VERY LOW }}{\oplus \bigcirc \bigcirc \bigcirc}$ & CRITICAL \\
\hline
\end{tabular}

Cl: Confidence interval; SMD: Standardised mean difference

a. There are some concerns due to randomization process, missing outcome data, measurement of the outcome (blinding of the outcome assessor), and selection of the reported result.

b. The sample size was not sufficient according to the optimal information size (OIS); the Cl cross the threshold of the magnitude of the effect. c. The effect estimates of individual studies were not similar, $95 \% \mathrm{Cl}$ did not overlap, there was statistically significant heterogeneity showed

Fig. 4: Summary of Finding (SoF) table showing the effect estimate together with the certainty of the evidence for pain 1-2 or 6-8 hours after the surgery.

\section{Discussion}

The control of postoperative pain, edema and trismus has been the subject of continuous research in the area of oral and maxillofacial surgery, since pain can significantly reduce the patient's quality of life $(3,15)$.

Tissue damage caused by the insertion of dental implants promotes the onset of an inflammatory process and, consequently, the release of several mediators such as prostaglandins (PGE) and bradykinins that sensitizes nociceptors (16). Anti-inflammatory drugs and local anesthetics inhibit the synthesis of mediators by inactivating the cyclooxygenase (COX) and phospholipase enzymes, altering nociception, and reducing peripheral sensitization. The decrease in the levels of inflammatory mediators at the site of tissue injury is strongly associated with these effects (17-19).

Our results showed that preemptive analgesia can slightly reduce pain 1-2 hours after implant surgery when compared to placebo. When assessing pain 6-8 hours after surgery, preventive analgesia proved to be effective, but the evidence was determined to be uncertain. Preemptive analgesia has been shown to be effective in reducing postoperative pain in the surgical removal of third molars $(3,20)$, despite some studies $(21,22)$ did not demonstrate a significant preemptive effect. Methodological differences may have an impact on these results, with divergence in the perception of postoperative pain. In dental implant placement, the preemptive analgesia protocol has considerably reduced the average pain scores, especially in the first 6 hours after the surgical procedure (3). A peak in prostaglandin E2 (PGE2) levels was observed approximately 3 hours after periodontal surgery and surgical removal of third molars $(23,24)$. The peak of maximum pain at sites of acute inflammation usually occurs around 3-4 hours, coinciding with the maximum concentration of prostaglandins (22).
Our meta-analysis showed that the magnitude of the effect was bigger for 6-8 hours after surgery (large effect) compared to 1-2 hours after surgery (small effect). Among the drugs used in the evaluated RCTs, two studies $(4,13)$ used Ibuprofen $600 \mathrm{mg}$ as preemptive medication. This non-steroidal anti-inflammatory drug (NSAID) inhibits the action of the COX enzyme, blocking the production of inflammatory mediators. It has a plasma half-life of 1 to 3 hours (25). The minimum plasma concentration of $26 \mu \mathrm{g} / \mathrm{ml}$ of ibuprofen is capable of producing analgesic effect, and a dose of Ibuprofen of $600 \mathrm{mg}$ has a maximum plasma level close to $69 \mu \mathrm{g} / \mathrm{ml}$, on average, between 2 and 3 hours after the initial dose (26). Our subgroup analysis showed that ibuprofen had large effect 1-2 hours after surgery, when compared to placebo. Significant differences in pain level were observed in the first 4 hours between the ibuprofen group compared to the placebo group, emphasizing the beneficial effect of preemptive analgesia with ibuprofen (4). Unfavorable results were obtained with $25 \mathrm{mg}$ of dexketoprofen trometamol (13), administered $15 \mathrm{~min}$ before the procedure for the period of 1-2 hours and 6-8 hours.

In a recent overview (27), it was shown that Ibuprofen $600 \mathrm{mg}$ had the highest proportion of patients (77\%) who achieved at least $50 \%$ of maximum pain relief for 4-6 hours, followed by combinations of $400 \mathrm{mg}$ of ibuprofen with $1,000 \mathrm{mg}$ of acetaminophen (72\%), $200 \mathrm{mg}$ ibuprofen with $500 \mathrm{mg}$ acetaminophen (69\%). The evaluation of the duration of pain relief showed that $1000 \mathrm{mg}$ of diflunisal, $650 \mathrm{mg}$ of acetaminophen, $500 \mathrm{mg}$ of diflunisal and 500 to $550 \mathrm{mg}$ of naproxen, had the longest duration of action. The doses of 600 to $650 \mathrm{mg}$ of acetaminophen, $25 \mathrm{mg}$ of potassium diclofenac, $60 \mathrm{mg}$ of codeine and $250 \mathrm{mg}$ of gabapentin, were those that obtained the shortest duration of the analgesic effect. 
The $25 \mathrm{mg}$ dexketoprofen trometamol also obtained positive results for postoperative pain relief in third molar surgeries (28). In our meta-analysis, piroxican was effective 6-8 hours postoperative, when compared to placebo.

There was inconsistency for pain control after 6-8 hours due to the high 12 , lack of overlap of the CIs and different individual effect estimates among studies (29). The heterogeneity may be explained by the different drugs used in the final pooled effect estimate. Moreover, there was serious imprecision for pain control after 1-2 hours and after 6-8 hours. In fact, the amplitude of CI showed that, for 1-2 hours, preemptive analgesia can have a moderate (lower CI: -0.71) to a trivial effect (upper CI: -0.15) compared to placebo. For 6-8 hours, preemptive analgesia can have a large (lower CI: -3.14 ) to a trivial effect (upper CI: -0.14) compared to placebo. Although in both cases the preemptive medication has a beneficial effect compared to placebo, the magnitude of the effect in reducing pain is too imprecise. In fact, pain is very subjective and can vary from patient to patient. Preemptive analgesia can have more benefits than harm compared to placebo, as pain after oral and maxillofacial surgery can affect the patient's quality of life $(3,15)$. However, for implant surgery, the evidence is uncertain due to the variation of the magnitude of the effect. There were also serious problems due to the risk of bias. The clinical trials had some concerns due to randomization process $(13,14)$, missing outcome data $(4,13)$, and selection of reported outcome, as no study reported a registered protocol previously to conducting the trials $(4,12-14)$. In addition, one studie had some concerns regarding blinding of the outcome assessor (12), while other study was at high risk of bias (4).

- Strengths and limitations:

This meta-analysis is limited due to the small number of included trials, which inputted imprecision on data. Furthermore, there was a variety of treatment protocols and methods for evaluating the results. One of the four selected studies could not be included in the metaanalysis as its data was provided in median values with non-normal distribution and not in mean values.

The present study has strengths as it uses the Cohen's classification for the magnitude of the effect together with GRADE guidelines to interpret data for the clinical practice (11). The small important effect of preemptive analgesia within 1-2 hours leads us to question some protocols, such as the standardization of the anesthetic drug, the number of implants and the area where they will be placed, since the surgical trauma can influence the results of preemptive analgesia $(3,15,27)$. The 4 studies included in this systematic review, $(4,12,13,14)$ included only cases of single-implant surgery and only one study (12) reported the region where the implants were placed. It is important to note that this can im- pact the bias risk assessment of studies without this information. Two meta-analyzes $(30,31)$ showed a better anesthetic effect of articaine $4 \%$ with epinephrine $1: 100,000$ compared to lidocaine $2 \%$ with epinephrine 1: 100,000 . In addition, the anesthetic technique used can also influence the perception of postoperative pain and mask the effects of preemptive analgesia. The alveolar nerve block, for example, presents a greater residual postoperative analgesia, when compared to the infiltrative techniques (32). Studies evaluating preemptive analgesia should consider this data during methodological planning and results interpretation and discussion. Ideally, the test and control groups should be comparable in relation to the surgical sites, consequently, in relation to the anesthetic techniques used. These findings lead us to question whether the use of a more potent anesthetic base can mask the effects of preemptive medication. For pain after 6-8 hours, we observed that preemptive medication may have little effect on the expected result, but the evidence is very uncertain.

The study with the largest sample (13) did not demonstrate significant effects of preemptive analgesia in the evaluated postoperative periods. In the qualitative analysis, it demonstrated limitations in relation to bias due to deviation from intended intervention and missing outcome data. Meta-analyzes allow gathering the results of several studies with a common objective and, therefore, their results have greater power than results from individual studies.

Preemptive analgesia remains a very controversial, but a timely topic. There are several preventive analgesia protocols in surgical procedures for dental implant placement, with great methodological differences between clinical trials. Among these main differences, the following ones stand out: periods of postoperative pain assessment, methods of drug administration and differences in local anesthetics and vasoconstrictors.

The preemptive analgesia is effective for pain control. However, the magnitude of the effect is imprecise and can vary from large to trivial effect. For the clinical practice, there are two factors that can influence pain control: the time of drug administration and the time length of the surgery. When the drug is administered closer to the surgery, the drug effect can be extended for longer periods. Also, shorter surgeries can influence the perceived pain by the patient when compared to longer surgeries with longer intra-oral manipulation and more implants placement.

For future studies, RCTs should properly randomize patients and provide the blinding of the outcome assessor (the patient) with standardized pills for the intervention and control groups. Moreover, for more transparency in the research protocol, authors should register the trial before starting the study. 


\section{Conclusions}

The preemptive analgesia may slightly reduce pain from one to two hours after surgery when compared to patients who did not use preemptive medication. After six to eight hours, the preemptive analgesia may have a large effect in reducing pain compared to not using preemptive medication. However, the evidence is very uncertain and very imprecise.

\section{References}

1. Lovich-Sapola J, Smith CE, Brandt CP. Postoperative pain control. Surg Clin North Am. 2015;95:301-18.

2. Rosero EB, Joshi GP. Preemptive, preventive, multimodal analgesia: What do they really mean?. Plast Reconstr Surg. 2014;134:85S-93S. 3. Cetira Filho EL, Carvalho FSR, de Barros Silva PG, Barbosa DAF, Alves Pereira KM, Ribeiro TR, et al. Preemptive use of oral nonsteroidal anti-inflammatory drugs for the relief of inflammatory events after surgical removal of lower third molars: A systematic review with meta-analysis of placebo-controlled randomized clinical trials. J Craniomaxillofac Surg. 2020;48:293-307.

4. Bahammam MA, Kayal RA, Alasmari DS, Attia MS, Bahammam LA, Hassan MH, et al. Comparison between dexamethasone and ibuprofen for postoperative pain prevention and control after surgical implant placement: A double-masked, parallel-group, placebocontrolled randomized clinical trial. J Periodontol. 2017;88:69-77.

5. Kelly DJ, Ahmad M, Brull SJ. Preemptive analgesia I: Physiological pathways and pharmacological modalities. Can J Anaesth. 2001;48:1000-10.

6. Campbell WI, Kendrick RW, Fee JP. Balanced pre-emptive analgesia: does it work? A double-blind, controlled study in bilaterally symmetrical oral surgery. Br J Anaesth.1998;81:727-30.

7. Page MJ, McKenzie JE, Bossuyt PM, Boutron I, Hoffmann TC, Mulrow CD, et al. The PRISMA 2020 statement: An updated guideline for reporting systematic reviews. BMJ. 2021;372:71.

8. Higgins JP, Thompson SG, Deeks JJ, Altman DG. Measuring inconsistency in meta-analyses. BMJ. 2003;327:557-60.

9. Zhang Y, Akl EA, Schünemann HJ. Using systematic reviews in guideline development: The GRADE approach [published online ahead of print, 2018 Jul 14]. Res Synth Methods. 2018.

10. Martins CC, Firmino RT, Riva JJ, Ge L, Carrasco-Labra A, Brignardello-Petersen R, et al. Desensitizing toothpastes for dentin hypersensitivity: A network meta-analysis. J Dent Res. 2020;99:514-22. 11. Santesso N, Glenton C, Dahm P, Garner P, Akl EA, Alper B, et al. GRADE Working Group. GRADE guidelines 26: Informative statements to communicate the findings of systematic reviews of interventions. J Clin Epidemiol. 2020;119:126-35.

12. Bhutani N, Sangolikar D, Bhutani S, Tapashetti R, Pushpalatha H. Sublingual piroxicam as preemptive analgesia in single implant surgery. J Contemp Dent Pract. 2019;20:750-53.

13. Sánchez-Pérez A, Muñoz-Peñalver J, Moya-Villaescusa MJ, Sánchez-Matás C. Effects of the preoperative administration of dexketoprofen trometamol on pain and swelling after implant surgery: A randomized, double-blind controlled trial. J Oral Implantol. 2018;44:122-29.

14. Mattos Pereira G, Cota LO, Lima RP, Costa FO. Effect of preemptive analgesia with ibuprofen in the control of postoperative pain in dental implant surgeries: A randomized, triple-blind controlled clinical trial. J Clin Exp Dent. 2020;12:e71-8.

15. Bailey E. Prevention and management of post-operative pain in oral surgery. Prim Dent J. 2018;7:57-63.

16. Ong CK, Seymour RA. An evidence-based update of the use of analgesics in dentistry. Periodontol 2000. 2008;46:143-64.

17. Sisk AL, Grover, BJ. A comparison of preoperative and postoperative naproxen sodium for suppression of postoperative pain. J Oral Maxillofac Surg. 1990;48:674-78.

18. Scott RE, Ellis E 3rd, Upton LG. Double-blind evaluation of etodolac $(200 \mathrm{mg}, 400 \mathrm{mg})$ compared with zomepirac $(100 \mathrm{mg})$ and placebo on third molar extraction pain. Oral Surg Oral Med Oral Pathol. 1986;62:638-42.

19. Kaczmarzyk T, Wichlinski J, Stypulkowska J, Zaleska M, Woron J. Preemptive effect of ketoprofen on postoperative pain following third molar surgery: A prospective, randomized, double-blinded clinical trial. Int J Oral Maxillofac Surg. 2010;39:647-52.

20. Santos BFE, Costa FO, Vasconcelos AMA, Cyrino RM, Cota LOM. Preemptive effects of ibuprofen and nimesulide on postoperative pain control after open flap periodontal surgeries: a randomized placebo-controlled split-mouth clinical trial. J Periodontol. 2021.

21. Aznar-Arasa L, Harutunian K, Figueiredo R, Valmaseda-Castellón E, Gay-Escoda C. Effect of preoperative ibuprofen on pain and swelling after lower third molar removal: a randomized controlled trial. Int J Oral Maxillofac Surg. 2012;41:1005-9.

22. Costa FW, Soares EC, Esses DF, Silva PG, Bezerra TP, Scarparo $\mathrm{HC}$, et al. A split-mouth, randomized, triple-blind, placebo-controlled study to analyze the pre-emptive effect of etoricoxib $120 \mathrm{mg}$ on inflammatory events following removal of unerupted mandibular third molars. Int J Oral Maxillofac Surg. 2015;44:1166-74.

23. O'Brien TP, Roszkowski MT, Wolff LF, Hinrichs JE, Hargreaves KM. Effect of a non-steroidal anti-inflammatory drug on tissue levels of immunoreactive prostaglandin E2, immunoreactive leukotriene, and pain after periodontal surgery. J Periodontol. 1996;67:1307-16.

24. Roszkowski MT, Swift JQ, Hargreaves KM. Effect of NSAID administration on tissue levels of immunoreactive prostaglandin E2, leukotriene B4, and (S)-flurbiprofen following extraction of impacted third molars. Pain. 1997;73:339-45.

25. Kantor TG. Ibuprofen. Ann Intern Med. 1979;91:877-82.

26. Laska EM, Sunshine A, Marrero I, Olson N, Siegel C, McCormick N. The correlation between blood levels of ibuprofen and clinical analgesic response. Clin Pharmacol Ther. 1986;40:1-7.

27. Moore PA, Ziegler KM, Lipman RD, Aminoshariae A, CarrascoLabra A, Mariotti A. Benefits and harms associated with analgesic medications used in the management of acute dental pain: An overview of systematic reviews. J Am Dent Assoc. 2018;149:256-65. 28. Jiménez-Martínez E, Gasco-García C, Arrieta-Blanco JJ, Gomez del Torno J, Bartolome Villar B. Study of the analgesic efficacy of dexketoprofen trometamol $25 \mathrm{mg}$. vs. ibuprofen $600 \mathrm{mg}$ after their administration in patients subjected to oral surgery. Med Oral. 2004;9:138-48.

29. Guyatt GH, Oxman AD, Kunz R, Woodcock J, Brozek J, Helfand M, et al. GRADE Working Group. GRADE guidelines: 7. Rating the quality of evidence--inconsistency. J Clin Epidemiol. 2011;64:1294302 .

30. Katyal V. The efficacy and safety of articaine versus lignocaine in dental treatments: A meta-analysis. J Dent. 2010;38:307-17.

31. St George G, Morgan A, Meechan J, Moles DR, Needleman I, Ng $\mathrm{YL}$, et al. Injectable local anaesthetic agents for dental anaesthesia. Cochrane Database Syst Rev. 2018;7:CD006487.

32. Figueiredo R, Sofos S, Soriano-Pons E, Camps-Font O, Sanmarti-García G, Gay-Escoda C, et al. Is it possible to extract lower third molars with infiltration anaesthesia techniques using articaine? A double-blind randomized clinical trial. Acta Odontol Scand. 2021;79:1-8. 


\section{Funding}

CCM, LOMC and FOC are research fellows at the National Council for Scientific and Technological Development (CNPq, Ministry of Education, Brazil $(\mathrm{CNPq})$. The funding agency had no role in the conception, acquisition of data and interpretation of the results.

\section{Conflict of interest}

The authors declare no conflict of interest.

\section{Authors contributions}

Gustavo Henrique de Matos-Pereira: Concept/design, data analysis/ interpretation, drafting the article, data extraction, critical revision of article, approval of article. Carolina Castro Martins: data analysis/ interpretation, statistics, drafting article, critical revision of article, approval of article. Rafael Paschoal Esteves-Lima: concept/design, data analysis/interpretation, data extraction, drafting article, critical revision of article, approval of article. Rachel Alvarenga Brant: data analysis/interpretation, data extraction, critical revision of article, approval of article. Luís Otávio Miranda Cota: concept/design, data analysis/interpretation, critical revision of article, approval of article. Fernando Oliveira Costa: concept/design, data analysis/interpretation, critical revision of article, approval of article. 